\title{
Dead space and slope indices from the expiratory carbon dioxide tension-volume curve
}

\author{
A.H. Kars*, J.M. Bogaard*, T. Stijnen**, J. de Vries*, A.F.M. Verbraak*, C. Hilvering*
}

Dead space and slope indices from the expiratory carbon dioxide tension-volume curve. A.H. Kars, J.M. Bogaard, T. Stijnen, J. de Vries, A.F.M. Verbraak, C. Hilvering. (CERS Journals Ltd 1997.

ABSTRACT: The slope of phase 3 and three noninvasively determined dead space estimates derived from the expiratory carbon dioxide tension $\left(\mathrm{PCO}_{2}\right)$ versus volume curve, including the Bohr dead space ( $V$ D,Bohr), the Fowler dead space ( $V D$,Fowler) and pre-interface expirate (PIE), were investigated in 28 healthy control subjects, 12 asthma and 29 emphysema patients ( 20 severely obstructed and nine moderately obstructed) with the aim to establish diagnostic value.

Because breath volume and frequency are closely related to $\mathrm{CO}_{2}$ elimination, the recording procedures included varying breath volumes in all subjects during self-chosen/natural breathing frequency, and fixed frequencies of 10,15 and 20 breaths $\mathrm{min}^{-1}$ with varying breath volumes only in the healthy controls.

From the relationships of the variables with tidal volume $(V T)$, the values at 1 $L$ were estimated to compare the groups. The slopes of phase 3 and $V D, B o h r$ at 1 L VT showed the most significant difference between controls and patients with asthma or emphysema, compared to the other two dead space estimates, and were related to the degree of airways obstruction. Discrimination between no-emphysema (asthma and controls) and emphysema patients was possible on the basis of a plot of intercept and slope of the relationship between $V \mathrm{D}, \mathrm{Bohr}$ and $V \mathrm{~T}$. A combination of both the slope of phase 3 and $V D, B o h r$ of a breath of $1 \mathrm{~L}$ was equally discriminating. The influence of fixed frequencies in the controls did not change the results.

The conclusion is that Bohr dead space in relation to tidal volume seems to have diagnostic properties separating patients with asthma from patients with emphysema with the same degree of airways obstruction. Equally discriminating was a combination of both phase 3 and Bohr dead space of a breath of $1 \mathrm{~L}$. The different pathophysiological mechanisms in asthma and emphysema leading to airways obstruction are probably responsible for these results.

Eur Respir J 1997; 10: 1829-1836.
*Dept of Pulmonary Diseases, University Hospital Dijkzigt Rotterdam, The Netherlands, **Dept of Biostatistics, Erasmus University Rotterdam, The Netherlands

Correspondence: A.H. Kars Dept of Pulmonary Diseases University Hospital Dijkzigt Dr. Molewaterplein 40 3015 GD Rotterdam

The Netherlands

Keywords: Asthma emphysema

expiratory carbon dioxide curve phase three slope respiratory dead space

Received: May 21996

Accepted after revision April 221997

Supported by a grant from the Medical Board of the University Hospital Dijkzigt, Rotterdam, The Netherlands.
Expiratory partial pressure curves for $\mathrm{CO}_{2}$ can be characterized by three phases: phase 1, without alveolar air; phase 2, with rapidly increasing amounts of alveolar air; and phase 3, the alveolar plateau, which has a slightly positive slope in healthy persons. The characteristic abnormal shape of the expiratory carbon dioxide tension $\left(\mathrm{PCO}_{2}\right)$ versus time curve in emphysema patients has been studied previously $[1,2]$ and has been attributed to serial, as well as parallel inhomogeneity. The dependence of the expiratory $\mathrm{PCO}_{2}$ versus time curve on expiratory flow has led to the use of the $P_{\mathrm{CO}_{2}}$ versus volume curve [3, 4]. Variables derived from phase 2 , the volumes expired between $25-50 \%$ and $25-75 \%$ of the end-tidal carbon dioxide tension $\left(P \mathrm{ET}, \mathrm{CO}_{2}\right)$, had insufficient diagnostic value to separate emphysema patients with severe and moderate airways obstruction from healthy controls and asthma patients [5].

The slope of phase 3 is known to be increased in asthma as well as emphysema, demonstrating the increased ventilation-perfusion inhomogeneity in these disorders. Relatively well ventilated parts with low $\mathrm{PCO}_{2}$ empty first, and less well-ventilated parts with high $\mathrm{PCO}_{2}$ empty last [6].

For the analysis of dead space and alveolar volume from a $\mathrm{PCO}_{2}$ versus volume curve, an apparent division may be made of the expired volume into a dead space part containing no $\mathrm{CO}_{2}$ and the remaining alveolar part.

The aim of the present study was to investigate the diagnostic value of the slope of phase 3 and of three types of dead space estimates, derived noninvasively from the $P \mathrm{ET}, \mathrm{CO}_{2}$ versus volume curve, the Bohr dead space $(V D, B o h r)[7,8]$, the Fowler dead space $(V D, F o w l e r)$ $[9,10]$ and pre-interface expirate (PIE) [11], in healthy controls, asthma patients and emphysema patients.

\section{Methods}

\section{Study population}

The healthy controls were 28 persons with no history of disease of cardiopulmonary origin. The patient groups 
comprised 12 asthma patients during exacerbation and 29 emphysema patients, 20 of whom had severe obstruction (forced expiratory volume in one second $(\mathrm{FEV} 1)<1.4 \mathrm{~L})$ and nine of whom had moderate obstruction. In five of the asthma patients the investigations were repeated after recovery. Mean values for anthropometric data, including age, gender, height and bodymass index (BMI: weight in $\mathrm{kg} /$ height in $\mathrm{m}^{2}$ ) are reported in table 1. The controls had normal spirometric values, although residual volume (RV) and functional residual capacity (FRC) values were relatively low. The asthma patients, however, were younger and mostly female; they all had FEV1 and FEV1/ vital capacity (VC) values within 1.5 standard deviations (SDS) of their reference values in the year before or after the exacerbation. The moderately obstructed emphysema patients were comparable in age and weight to the severely obstructed emphysema patients, but had better FEV1 values, which were similar to the asthma patients during exacerbation.

The severely obstructed emphysema patients were mostly male, characterized by a relatively low body weight, reflected by their BMI. They had severe obstruction and hyperinflation. Blood gas values indicated primarily hypoxaemia without overall alveolar hypoventilation.

\section{Clinical diagnosis}

For the diagnosis of emphysema, the clinical criteria of the American Thoracic Society (ATS) for chronic obstructive pulmonary disease (COPD) [12] and the radiographical criteria described by PRATT [13] were used: the latter are based on signs of hyperinflation and tissue loss on the posteroanterior and lateral chest radiograph. On the posteroanterior radiograph, two signs can be distinguished: 1) depression and flattening of the diaphragm with blunting of costophrenic angles; and 2) irregular radiolucency of lung fields. On the lateral radiograph two signs may be present: 1) abnormal retrosternal space; and 2) flattening or even concavity of the diaphragm. The diagnosis of emphysema was made if two or more of these criteria were present. Asthma was diagnosed according to ATS criteria [12]: a clinical syndrome characterized by increased responsiveness of the tracheobronchial tree to a variety of stimuli, with symptoms of paroxysmal dyspnoea, wheezing and cough and, as a physiological manifestation of this hyperresponsiveness, variable airway obstruction. Only those patients in whom no airway obstruction was found before or after the exacerbation were selected for the study. All healthy controls older than 50 yrs had a chest radiograph to exclude pulmonary pathology.

\section{Pulmonary function tests}

Pulmonary function tests in the controls and patient groups included spirometry with estimation of total lung capacity (TLC), FRC, RV, VC, and $\mathrm{FEV}_{1}$. Functional residual capacity and RV were measured using the closed circuit helium dilution method. Mean values and SDS, of the pulmonary function variables are given in table 1. Transfer factor (single breath method) was measured in all moderated obstructed emphysema patients, but was possible with sufficient accuracy in only seven of the severely obstructed emphysema patients. This resulted in transfer factor of the lung for carbon monoxide $(T \mathrm{~L}, \mathrm{CO})$ values per litre of effective alveolar volume of $75 \%(\mathrm{SD} \pm 25 \%)$ and $70 \%(\mathrm{SD} \pm 24 \%)$ of reference values, respectively. Reference values for spirometry were the European Coal and Steel Community (ECSC) values [14].

\section{Measuring equipment}

The measuring equipment consisted of $\mathrm{a} \mathrm{CO}_{2}$ analyser (Capnometer 47210A; Hewlett Packard, Palo Atto, USA) in series with a pneumotachometer head (Jaeger, Würzburg, Germany) connected to a pressure transducer (model DP 15, Validyne Corp., Northridge, CA, USA). Both signals were sampled with a frequency of $50 \mathrm{~Hz}$ and analysed by computer (PDP11, Digital Equipment Corporation, MA, USA). Flow was integrated to volume. A fixed time delay of $160 \mathrm{~ms}$ was needed to synchronize the $\mathrm{CO}_{2}$ signal with the flow signal. The

Table 1. - Data on the study population

\begin{tabular}{|c|c|c|c|c|c|c|c|c|}
\hline \multirow{3}{*}{$\begin{array}{l}\text { Age yrs } \\
\text { Gender } \mathrm{M} / \mathrm{F}\end{array}$} & \multicolumn{2}{|c|}{ Healthy controls } & \multicolumn{2}{|c|}{$\begin{array}{l}\text { Asthma patients } \\
\text { during exacerbation }\end{array}$} & \multicolumn{2}{|c|}{$\begin{array}{l}\text { Moderately obstructed } \\
\text { emphysema patients }\end{array}$} & \multicolumn{2}{|c|}{$\begin{array}{l}\text { Severely obstructed } \\
\text { emphysema patients }\end{array}$} \\
\hline & 51 & (17) & $36 *$ & (14) & 54 & (10) & 60 & (12) \\
\hline & \multicolumn{2}{|c|}{$17 / 11$} & \multicolumn{2}{|c|}{$4 / 8$} & \multicolumn{2}{|c|}{$7 / 2$} & \multicolumn{2}{|c|}{$18 / 2$} \\
\hline Height $\mathrm{m}$ & 1.72 & $(0.10)$ & 1.72 & $(0.13)$ & 1.78 & $(0.08)$ & 1.73 & $(0.08)$ \\
\hline $\mathrm{BMI} \mathrm{kg} \cdot \mathrm{m}^{-2}$ & 24.8 & $(2.7)$ & 23.7 & $(2.9)$ & $21.7 *$ & $(2.9)$ & $21.1^{*}$ & $(3.5)$ \\
\hline TLC \% pred & 102 & (8) & 103 & (11) & $132 *$ & $(15)$ & $123 *$ & (11) \\
\hline $\mathrm{L}^{1}$ & 6.4 & (1.4) & 6.3 & $(2.0)$ & $9.2 *$ & $(1.7)$ & $8.2 *$ & $(1.1)$ \\
\hline FRC/TLC \% pred & 88 & (12) & $101 *$ & (15) & $118^{*}$ & (9) & $126^{*}$ & (14) \\
\hline$\%$ & 47 & (6) & 51 & (10) & $65^{*}$ & (5) & $70^{*}$ & (8) \\
\hline RV/TLC \% pred & 87 & (12) & $101 *$ & (22) & $138^{*}$ & (22) & $150^{*}$ & (34) \\
\hline$\%^{1}$ & 30 & (7) & 30 & (12) & 48 & (7) & $54 *$ & (10) \\
\hline VC \% pred & 114 & (13) & $89 *$ & (18) & 106 & (13) & $87 *$ & (16) \\
\hline $\mathrm{L}^{1}$ & 4.6 & $(1.2)$ & $3.7 *$ & $(1.4)$ & 4.8 & $(1.0)$ & $3.6^{*}$ & $(0.8)$ \\
\hline FEV1 \% pred & 106 & (11) & $57 *$ & (17) & $61^{*}$ & (12) & $29^{*}$ & (11) \\
\hline $\mathrm{L}^{\mathrm{I}}$ & 3.3 & $(1.0)$ & $2.0 *$ & $(0.9)$ & $2.1 *$ & $(0.5)$ & $0.9 *$ & $(0.3)$ \\
\hline $\mathrm{FEV}_{1} / \mathrm{VC} \%$ & 74 & (7) & $53 *$ & (9) & $44 *$ & (6) & $25^{*}$ & (7) \\
\hline
\end{tabular}

Values are presented as mean, with SD in parenthesis, with the exception of gender, which is given as absolute number. *: p<0.05, compared to controls. BMI: body mass index; TLC: total lung capacity; FRC: functional residual capacity; RV: residual volume; VC: vital capacity; FEV1: forced expiratory volume in one second; \% pred: percentage of predicted value; M: male; F: female. 
pneumotachometer head was heated to a constant temperature of $37^{\circ} \mathrm{C}$. As the temperature and humidity of the gas in the pneumotachometer head are difficult to estimate, a humidity of $50 \%$ and a mean temperature of $30^{\circ} \mathrm{C}$ for the inspired gas were assumed. From these values and the current barometric pressure, values for inspired air were corrected for body temperature and ambient pressure, and saturated with water vapour (BTPS). For the expiratory gas, BTPS conditions were present. Calibration with a $1 \mathrm{~L}$ syringe was performed before each measurement.

Because volume integration was performed over a relatively large number of breaths, volume drift had to be corrected. Assuming an unchanged RV during the test, a correction factor was established based on RV level after maximal expiration both at the beginning and end of the procedure [5]. The accuracy of the volume estimation was controlled with a spirometer in series; the volume measured by the pneumotachograph was slightly, but not systematically, different and appeared to be within about $5 \%$ of the volume measured by the spirometer.

The dead space volume of mouthpiece, $\mathrm{CO}_{2}$ analyser and pneumotachometer head was $50 \mathrm{~mL}$.

\section{Slope of phase 3 and three dead space estimates}

The slope of phase 3 was calculated by linear regression analysis of the data points between 60 and $90 \%$ of the expiratory volume. The dead space estimates (Bohr, Fowler and PIE) are explained in figure 1. The PIE was estimated according to WoLFF and BRUNNER [11].

a)

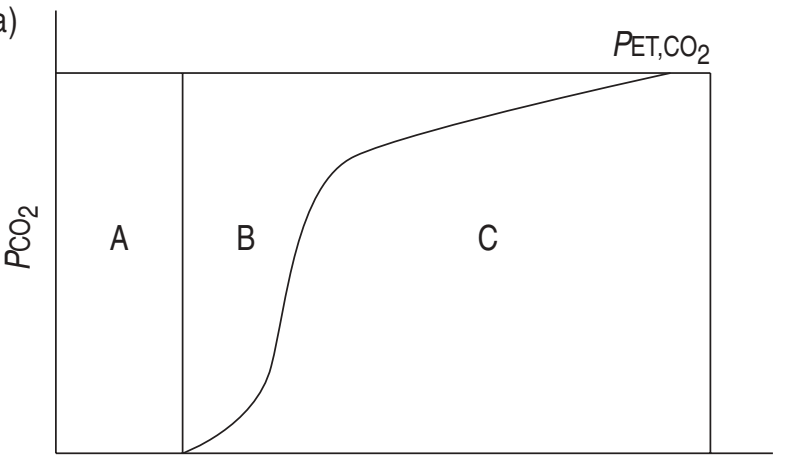

VE

c)

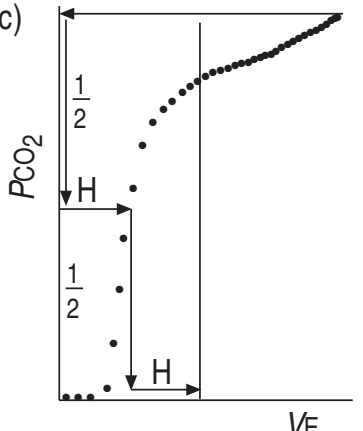

Firstly, the curve was truncated at twice the volume at which $\mathrm{PCO}_{2}$ was half $P \mathrm{ET}, \mathrm{CO}_{2}$ (fig. 1c, first panel). To find an index of the steepest slope, this slope $\left(\Delta P \mathrm{CO}_{2} / \Delta V\right)$ was calculated and plotted against expired volume, whereafter the mean value of the slope-expiratory volume $(V E)$ distribution was estimated (fig. 1c, second and third panels). This value was assumed to be associated with the volume boundary of the transition of the conductive to gas exchange zone.

\section{Experimental protocol}

Because breath volume and frequency are closely related to $\mathrm{CO}_{2}$ elimination, the procedures of recording included varying breath volumes in all subjects during self-chosen/natural breathing frequency, and fixed frequencies of 10,15 and 20 breaths. $\mathrm{min}^{-1}$ with varying breath volumes only in the healthy controls. In this way, we were able to define the relationships of the variables with tidal volume $(V \mathrm{~T})$ and breathing frequency.

Each test consisted of a series of 40-80 consecutive breaths during spontaneous breathing with natural breathing frequency. After each 3-5 normal breaths the subject was asked to take a deep breath from FRC level with return to FRC level and then breathe normally again. In this way, an appreciable range of inspiratory tidal volumes was obtained. The control group repeated these manoeuvres while breathing at fixed frequencies of 10 , 15 and 20 breaths $\cdot \mathrm{min}^{-1}$. The latter manoeuvres could not be performed adequately by the patients because of their expiratory obstruction.

b)
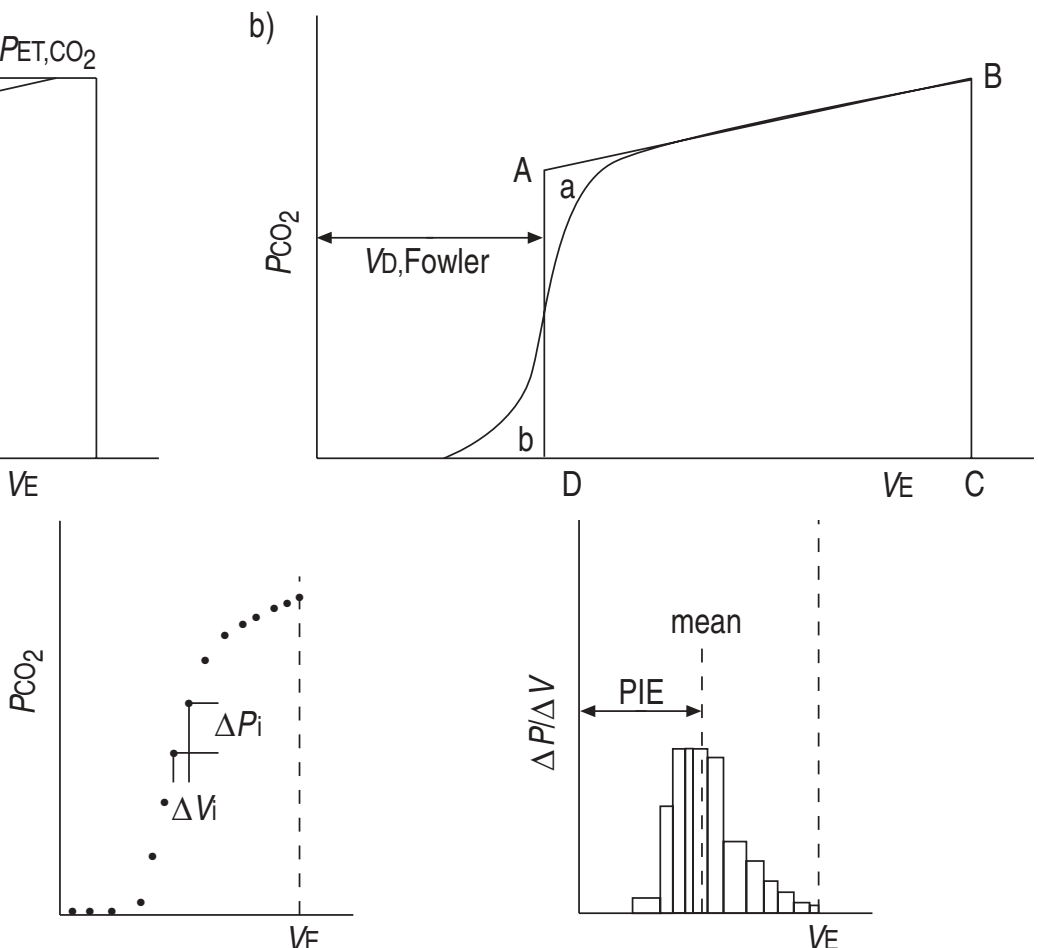

Fig. 1. - Graphic representations of the derivation of the dead space estimates Bohr dead space (VD,Bohr), Fowler dead space ( $V \mathrm{D}$,Fowler), and pre-interface expirate $(\mathrm{PIE})$, a) $V_{\mathrm{D}, \mathrm{Bohr}}=$ part of the expiratory volume $(V \mathrm{E})$ without $\mathrm{CO}_{2}=V \mathrm{E}(\mathrm{A}+\mathrm{B}) /(\mathrm{A}+\mathrm{B}+\mathrm{C})=V \mathrm{E}(1-\mathrm{C} /(\mathrm{A}+\mathrm{B}+\mathrm{C}))$ with areas $\mathrm{A}, \mathrm{B}$ and $\mathrm{C}$. b) $V \mathrm{D}$,Fowler is calculated by forming a trapezium with the same surface area as the $\mathrm{CO}_{2}$ volume area under the curve (area $\mathrm{C}$ in fig. 1a). The height of the trapezium determines the position of the line, which yields equal areas a and b. c) PIE was estimated according to WoLfF and BRUNNER [11] as the mean value of a function of the slope of the carbon dioxide tension $\left(P \mathrm{CO}_{2}\right)$ volume $(V)$ curve $\left(\Delta P \mathrm{CO}_{2} / \Delta V\right)$ versus expired volume. Both the slope calculations from the data points and the distribution function of $\Delta P \mathrm{CO}_{2} / \Delta V$ versus tidal volume $(V \mathrm{~T})$ are presented. $\Delta V \mathrm{i}$ : volume intercept from ith interval; $\Delta P \mathrm{i}$ : pressure intercept from ith interval. $\mathrm{H}: V \mathrm{E}$ at $P \mathrm{CO}_{2}=$ half $P$ ET.CO . For further explanation see text. 


\section{Data analysis}

Analysis of phase $3, V \mathrm{D}$,Bohr, $V \mathrm{D}$,Fowler and PIE (fig. 1) was performed by computer in all breaths. A breath was rejected if there was a difference between inspiratory and expiratory volume of $>300 \mathrm{~mL}$. In case of $V \mathrm{D}$,Fowler, only breaths $\geq 750 \mathrm{~mL}$ were evaluated, as has been explained before. Data analysis in controls (natural breathing frequency and fixed frequencies) and patients (natural breathing frequency only) included the following: 1) Calculation of the linear relationships between the four variables and $V \mathrm{~T}$, resulting in an intercept and slope (the change per litre of $V \mathrm{~T}$ ) of these relationships for each individual; 2) Comparison of the values of the four variables at $1 \mathrm{~L} V \mathrm{~T}$ during natural breathing in the healthy controls with those of the patient groups. These values were obtained from the linear relationships with $V \mathrm{~T}$. The relationships of these values were evaluated at $1 \mathrm{~L} V \mathrm{~T}$ with FEV1 percentage predicted (\% pred) and FEV1/VC. The values of the four variables were compared at $1 \mathrm{~L} V \mathrm{~T}$ during natural breathing in the healthy controls with the values at $1 \mathrm{~L} V \mathrm{~T}$ during fixed frequencies; 3) Evaluation of the influence of preceding breaths by calculating the values of the slope of phase 3 and the three dead space estimates at the start of the procedure and after $5 \mathrm{~min}$. Tidal breaths of about equal size were selected; and 4) Evaluation in the control group of the linear relationship between the four variables at $1 \mathrm{~L} \mathrm{VT}$, and height and age, respectively.

\section{Statistical analysis}

Linear regression analysis was used to determine the relationship between the four variables and $V \mathrm{~T}$, which resulted in a slope and intercept for each individual. From these linear regression equations, the mean values at $1 \mathrm{~L} V \mathrm{~T}$ were calculated. To evaluate the influence of previous manoeuvres, the linear relationship with time was determined for the four variables in $V \mathrm{~T} \geq 750$ $\mathrm{mL}$ and within a range of $250 \mathrm{~mL}$. The mean values at time 0 and after $5 \mathrm{~min}$ were compared. This was only done in the healthy controls during natural breathing frequency and in the severely obstructed emphysema patients. The relationships between the four variables at a $V \mathrm{~T}$ of $1 \mathrm{~L}$, and $\mathrm{FEV}_{1} \%$ pred, $\mathrm{FEV} 1 /$ $\mathrm{VC}$, height and age, were also evaluated with linear regression analysis.

The two-sample t-test was used to investigate differences between two groups. The paired t-test was applied to investigate differences within a group. Because multiple comparisons were made in the patient groups and controls, the Bonferoni correction for multiple comparison was used. Discriminant analysis was applied on slope and intercept of the relationships between the three dead space estimates and $V \mathrm{~T}$ in healthy controls and severely obstructed emphysema patients.

$(\mathrm{n}=20)$

\section{Results}

For the linear relationships between the four variables (slope of the alveolar plateau and the three dead space estimates) and $V \mathrm{~T}$ we found in nearly all cases a significant linear correlation which enabled us to derive reliable slopes and values at $1 \mathrm{~L} V \mathrm{~T}$. The means of these slopes with SD are indicated in table 2. From these means and SDs either a significant increase, decrease or no change of the variable with $V \mathrm{~T}$ was concluded. The slopes of the alveolar plateaux decreased significantly in all groups; the decrease was larger in patients with airways obstruction. In all groups, except for $V D$,Fowler in the severely obstructed emphysema patients, the dead space estimates increased significantly with increase of $V \mathrm{~T}$ (p-values ranging from $<0.05$ to $<0.001)$. The increase of $V \mathrm{D}$,Bohr was similar in all groups and considerably larger than the increase per litre of $V D$,Fowler and PIE. Significantly larger values $(p<0.05)$, compared to the values in healthy controls during natural breathing frequency, were found only for the increase in $V \mathrm{D}$, Bohr in asthma patients during relapse. The increase per litre of the other two dead space estimates did not differ significantly in the patient groups compared to the controls. Although in the emphysema patients, the increases of $V$ D,Fowler and PIE with $V$ T were lower than in the other patient groups, no significance was reached for the differences with the controls during natural breathing frequency.

Discriminant analysis applied to the slope and intercept of the relationships of the dead spaces with $V \mathrm{~T}$ showed that $V \mathrm{D}$,Bohr had the largest discriminatory power in separating healthy controls from severely obstructed emphysema patients (fig. 2a). In case of $V D$,Fowler and PIE a larger number of misclassifications occurred. The same discriminant line appeared to locate all but two $(22 \%)$ moderately obstructed emphysema patients at the emphysema side of the line, and all but three

Table 2. - Mean changes of the slopes of the alveolar plateaux and dead space estimates per litre increase of tidal volume

\begin{tabular}{|c|c|c|c|c|}
\hline \multicolumn{2}{|c|}{$\begin{array}{l}\text { Slope of alveolar } \\
\text { plateaux } \mathrm{kPa} \cdot \mathrm{L}^{-1}\end{array}$} & \multirow[t]{2}{*}{$\begin{array}{l}V \mathrm{D}, \mathrm{Bohr} \\
\mathrm{mL} \cdot \mathrm{L}^{-1}\end{array}$} & \multirow[t]{2}{*}{$\begin{array}{l}\text { VD,Fowler } \\
\mathrm{mL} \cdot \mathrm{L}^{-1}\end{array}$} & \multirow[t]{2}{*}{$\begin{array}{l}\text { PIE } \\
\mathrm{mL} \cdot \mathrm{L}-\end{array}$} \\
\hline Controls & & & & \\
\hline Natural breathing $(n=28)$ & $\begin{array}{l}-0.22 * * * \\
(0.03)\end{array}$ & $\begin{array}{c}184 * * * \\
(10)\end{array}$ & $\begin{array}{l}30 * * * \\
(4)\end{array}$ & $\begin{array}{l}39 * * * \\
(7)\end{array}$ \\
\hline 10 breaths $\cdot \min ^{-1}(n=27)$ & $\begin{array}{c}-0.19 * * * \\
(0.02)\end{array}$ & $\begin{array}{c}184 * * * \\
(9)\end{array}$ & $\begin{array}{l}45^{* * * *} \\
(6)\end{array}$ & $\begin{array}{c}34 * * * \\
(4)\end{array}$ \\
\hline 15 breaths $\cdot \min ^{-1}(n=26)$ & $\begin{array}{c}-0.20 * * * \\
(0.02)\end{array}$ & $\begin{array}{c}186^{* * * *} \\
(9)\end{array}$ & $\begin{array}{c}42 * * * \\
(5)\end{array}$ & $\begin{array}{l}59 * * * \\
(20)\end{array}$ \\
\hline 20 breaths $\cdot \min ^{-1}(n=26)$ & $\begin{array}{c}-0.17 * * * \\
(0.03)\end{array}$ & $\begin{array}{c}192 * * * \\
(5)\end{array}$ & $\begin{array}{l}53 * * * \\
(5)\end{array}$ & $\begin{array}{l}54 * * * \\
(4)\end{array}$ \\
\hline $\begin{array}{l}\text { Asthma patients during } \\
\text { exacerbation }(\mathrm{n}=12)\end{array}$ & $\begin{array}{l}-0.51 * * * \\
(0.06)\end{array}$ & $\begin{array}{l}225 * * * \\
(16)\end{array}$ & $\begin{array}{l}36 * * \\
(11)\end{array}$ & $\begin{array}{c}30 * * \\
(8)\end{array}$ \\
\hline $\begin{array}{l}\text { Asthma patients after } \\
\text { recovery }(n=5)\end{array}$ & $\begin{array}{l}-0.39^{*} \\
(0.11)\end{array}$ & $\begin{array}{l}192 * * * \\
(19)\end{array}$ & $\begin{array}{l}35^{*} \\
(10)\end{array}$ & $\begin{array}{l}41 * \\
(51)\end{array}$ \\
\hline $\begin{array}{l}\text { Moderately obstructed } \\
\text { emphysema patients } \\
(\mathrm{n}=9)\end{array}$ & $\begin{array}{c}-0.54 * * * \\
(0.12)\end{array}$ & $\begin{array}{c}180 * * * \\
(16)\end{array}$ & $\begin{array}{l}26 * * \\
(7)\end{array}$ & $\begin{array}{l}14^{*} \\
(5)\end{array}$ \\
\hline $\begin{array}{l}\text { Severely obstructed } \\
\text { emphysema patients }\end{array}$ & $\begin{array}{l}-1.35 * * * \\
(0.20)\end{array}$ & $\begin{array}{c}185^{* * *} \\
(14)\end{array}$ & $\begin{array}{l}11 \mathrm{NS} \\
(12)\end{array}$ & $\begin{array}{l}21^{*} \\
(9)\end{array}$ \\
\hline
\end{tabular}

Values are presented as mean, with SD in parenthesis. $*: \mathrm{p}<0.05, * *: \mathrm{p}<0.01, * * *$ : $\mathrm{p}<0.001$, for test of hypothesis that the mean change is zero. NS: nonsignificant; VD,Bohr: Bohr dead space; VD,Fowler: Fowler dead space; PIE: pre-interface expirate. 

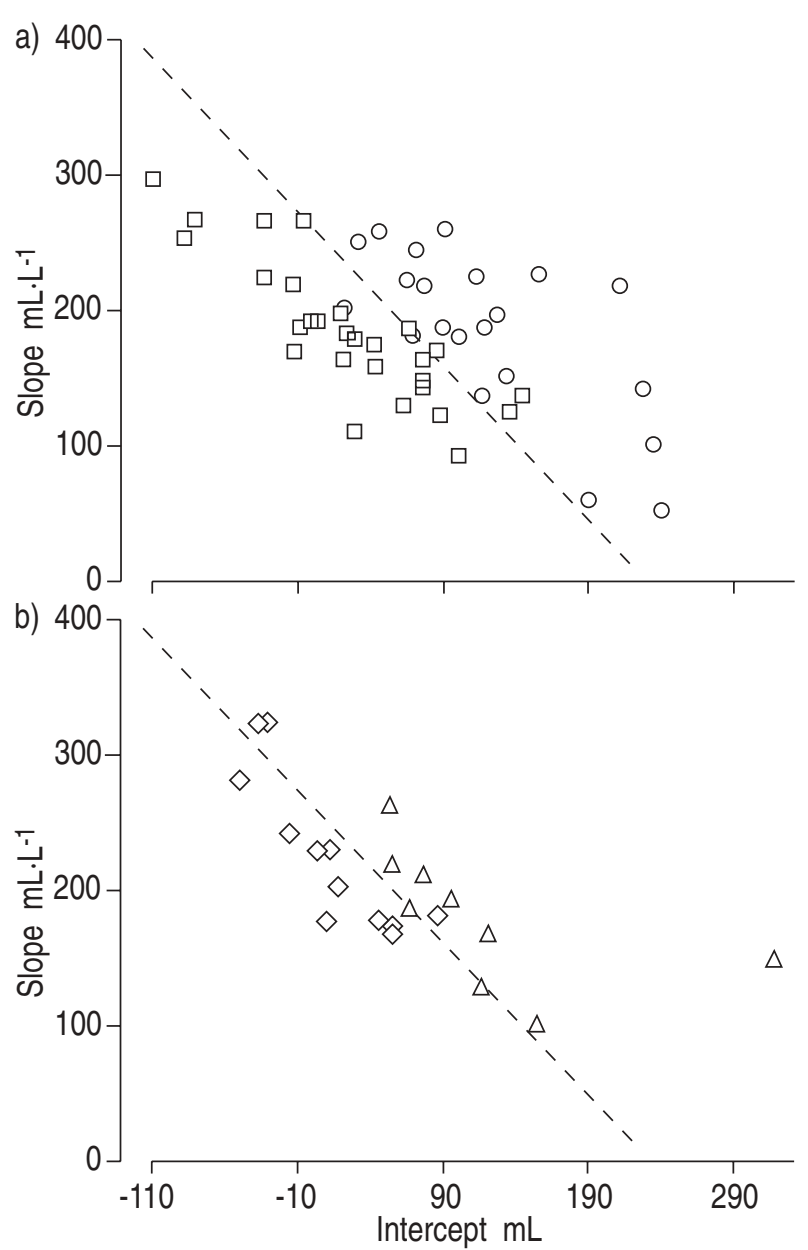

Fig. 2. - a) Slope versus intercept of the relationships of Bohr dead space $(V \mathrm{D}, \mathrm{Bohr})$ with tidal volume $(V \mathrm{~T})$ in healthy controls $(\square)$ and severely obstructed emphysema patients $(\bigcirc)$. b) Slope versus intercept of the relationships of $V \mathrm{D}$,Bohr with $V \mathrm{~T}$ in asthma patients during relapse $(\diamond)$ and moderately obstructed emphysema patients $(\Delta)$. - - - : discriminant line, determined with discriminant analysis applied to intercept and slope of the relationships between $V \mathrm{D}$,Bohr and $V_{\mathrm{T}}$ in healthy controls and severely obstructed emphysema patients. Intercept $\times 0.028$ + Slope $\times 26.05 \times 10^{-3}-6.58=0$.

$(25 \%)$ asthma patients with relapse at the healthy control side of the line (fig. $2 b$ ).

In table 3 the mean values (SEM) of the four variables at $1 \mathrm{~L} V \mathrm{~T}$ are presented for healthy controls and patient groups. The slopes of the alveolar plateaux were significantly increased in all groups with airways obstruction, and decreased in the healthy controls during breathing at fixed frequencies. The mean $V D$,Bohr values at $1 \mathrm{~L}$ were significantly higher than those for $V \mathrm{D}$,Fowler and PIE $(\mathrm{p}<0.001)$, the latter two estimates showing no significant difference compared to each other. Compared to the values in healthy controls during breathing at natural frequency, significant increase of the dead space estimates only occurred in the emphysema patients. For $V \mathrm{D}, \mathrm{Bohr}$, compared to $V \mathrm{D}$,Fowler and PIE, the increase was more significant in the moderately obstructed emphysema patients.
Discriminant analysis applied to the values of the slope of the alveolar plateau and $V \mathrm{D}$,Bohr in breaths of $1 \mathrm{~L} V \mathrm{~T}$ gave comparable discriminatory power for the separation of healthy controls from severely obstructed emphysema patients, and asthma patients from moderately obstructed emphysema patients, as shown in fig. 2 .

The relationship between the four variables at $1 \mathrm{~L} V \mathrm{~T}$ and $\mathrm{FEV}_{1}$ expressed as a percentage of predicted and as a percentage of the actual VC, was significant. For the slope of the alveolar plateau, the correlation coefficient was $-0.69(p<0.001)$. The best correlation for the dead space estimates was found between $V D$,Bohr and $\mathrm{FEV}_{1} / \mathrm{VC}$ (fig. 3) with $\mathrm{r}=-0.66$ ( $\mathrm{p}$-value $<0.0001$ ) versus $-0.32(\mathrm{p}<0.01)$ and $-0.43(\mathrm{p}<0.001)$ for $V \mathrm{D}$, Fowler and PIE, respectively.

The effects of breathing frequency on the four variables at $1 \mathrm{~L} V \mathrm{~T}$ in the controls are presented in table 3 . Comparison was made with the values during breathing at natural frequency, which was about 15 breaths $\cdot \mathrm{min}^{-1}$, in the short period before the start of the breathing manoeuvres. The slopes of the alveolar plateaux decreased during breathing at all fixed frequencies. At a breathing frequency of 10 breaths $\cdot \mathrm{min}^{-1}$, a slight decrease of all dead space estimates at $1 \mathrm{~L} V \mathrm{~T}$ was found. This was significant for $V D$,Fowler and PIE. At a frequency of 15 breaths. $\min ^{-1}$, changes were not significant, whereas during an increased breathing frequency of 20 breaths. min $^{-1}$ a significant increase of all dead space estimates was found, resulting in overlap with the values of emphysema patients for $V \mathrm{D}$, Fowler and PIE, but not for $V$ D,Bohr.

In 22 healthy controls and 15 severely obstructed emphysema patients, sufficient (seven or more) breaths with volumes of about equal size could be obtained for evaluation. In both groups, after $5 \mathrm{~min}$ there was a significant decrease of $P$ ET, $\mathrm{CO}_{2}, 0.97 \mathrm{kPa}(\mathrm{SEM} \pm 0.14)$ and $0.33 \mathrm{kPa}(\mathrm{SEM} \pm 0.08)$ in healthy controls $(\mathrm{p}<0.001)$ and emphysema patients $(\mathrm{p}<0.001)$, respectively. In the 22 healthy controls, the calculated mean value of the selected $V$ Ts was $896 \mathrm{~mL}$ (SEM \pm 24$)$. In the 15 emphysema

Table 3. - Mean values of the slopes of the alveolar plateaux and dead space estimates at $1 \mathrm{~L}$ tidal volume $(\mathrm{V} T)$

\begin{tabular}{|c|c|c|c|c|}
\hline & $\begin{array}{l}\text { Slope of alveolar } \\
\text { plateaux } \mathrm{kPa} \cdot \mathrm{L}^{-1}\end{array}$ & $\begin{array}{l}\text { VD,Bohr } \\
\mathrm{mL}\end{array}$ & $\begin{array}{l}V \text { D,Fowler } \\
\mathrm{mL}\end{array}$ & $\begin{array}{l}\text { PIE } \\
\mathrm{mL}\end{array}$ \\
\hline \multicolumn{5}{|l|}{ Controls } \\
\hline Natural breathing $(\mathrm{n}=28)$ & $\begin{array}{l}0.75 \\
(0.05)\end{array}$ & $\begin{array}{l}210 \\
(6)\end{array}$ & $\begin{array}{l}154 \\
(6)\end{array}$ & $\begin{array}{l}152 \\
(7)\end{array}$ \\
\hline 10 breaths $\cdot \mathrm{min}^{-1}(\mathrm{n}=27)$ & $\begin{array}{l}0.59 * * \\
(0.03)\end{array}$ & $\begin{array}{l}195 \\
(9)\end{array}$ & $\begin{array}{c}136^{*} \\
(7)\end{array}$ & $\begin{array}{c}132 * * \\
(7)\end{array}$ \\
\hline 15 breaths $\cdot \mathrm{min}^{-1}(\mathrm{n}=26)$ & $\begin{array}{r}0.60 * * \\
(0.03)\end{array}$ & $\begin{array}{l}213 \\
(6)\end{array}$ & $\begin{array}{l}159 \\
(7)\end{array}$ & $\begin{array}{l}162 \\
(11)\end{array}$ \\
\hline 20 breaths $\cdot \min ^{-1}(\mathrm{n}=26)$ & $\begin{array}{c}0.60 * * \\
(0.04)\end{array}$ & $\begin{array}{l}236^{* * * *} \\
(6)\end{array}$ & $\begin{array}{c}175^{*} \\
(9)\end{array}$ & $\begin{array}{l}187 * * * \\
(9)\end{array}$ \\
\hline $\begin{array}{l}\text { Asthma patients during } \\
\text { exacerbation }(n=12)\end{array}$ & $\begin{array}{l}1.22 * * * \\
(0.09)\end{array}$ & $\begin{array}{l}237 \\
(8)\end{array}$ & $\begin{array}{l}133 \\
(9)\end{array}$ & $\begin{array}{l}127 \\
(14)\end{array}$ \\
\hline $\begin{array}{l}\text { Asthma patients after } \\
\text { recovery }(n=5)\end{array}$ & $\begin{array}{c}0.94 \\
(0.15)\end{array}$ & $\begin{array}{l}223 \\
(17)\end{array}$ & $\begin{array}{l}153 \\
(16)\end{array}$ & $\begin{array}{l}158 \\
(27)\end{array}$ \\
\hline $\begin{array}{l}\text { Moderately obstructed } \\
\text { emphysema patients }(n=9)\end{array}$ & $\begin{array}{l}1.25^{* *} \\
(0.18)\end{array}$ & $\begin{array}{l}295^{* * * *} \\
(22)\end{array}$ & $\begin{array}{r}212 * \\
(29)\end{array}$ & $\begin{array}{r}229 * \\
(37)\end{array}$ \\
\hline $\begin{array}{l}\text { Severely obstructed } \\
\text { emphysema patients }(n=20)\end{array}$ & $\begin{array}{c}1.88 * * * \\
(0.18)\end{array}$ & $\begin{array}{l}300 * * * \\
(9)\end{array}$ & $\begin{array}{l}196^{* * * *} \\
(7)\end{array}$ & $\begin{array}{l}218 * * * \\
(12)\end{array}$ \\
\hline
\end{tabular}

Values are presented as mean, with SEM in parenthesis. ${ }^{*}$ : $\mathrm{p}<0.05,{ }^{* *} \mathrm{p}<0.01,{ }^{*} * * \mathrm{p}<0.001$ compared to the mean values of controls during natural breathing frequency. 


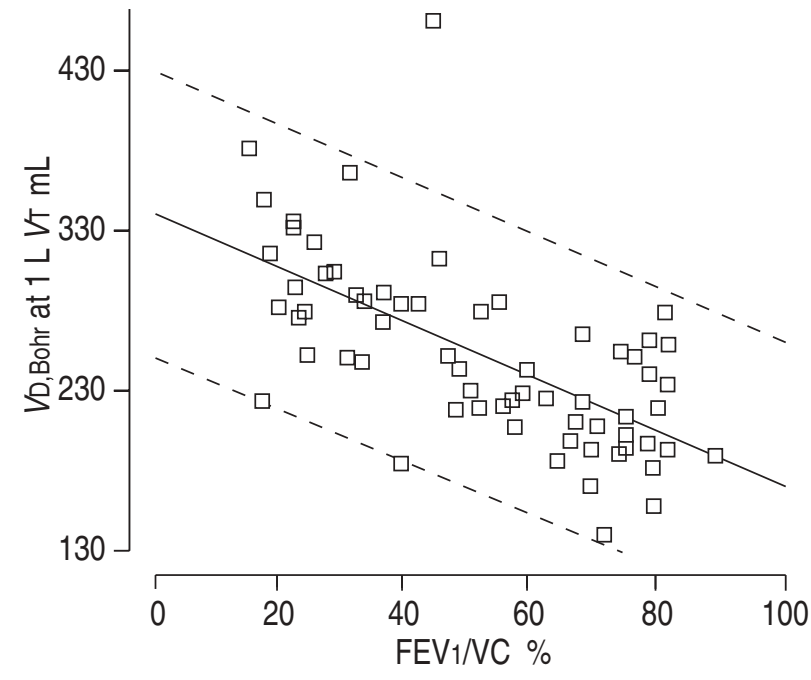

Fig. 3. - Relationship between $V \mathrm{D}, \mathrm{Bohr}$ at $1 \mathrm{~L} V \mathrm{~T}$ and $\mathrm{FEV} 1 / \mathrm{VC}$ in the study population. The relationship is: $V \mathrm{D}, \operatorname{Bohr}(\mathrm{mL})=342-1.71$ $\times \mathrm{FEV}_{1} / \mathrm{VC}(\%), \mathrm{p}<0.0001, \mathrm{r}^{2}=43 \%$. - - : lines representing $2 \mathrm{SD}$. $V$ D,Bohr: Bohr dead space; $V_{\mathrm{T}}$ : tidal volume; FEV1: forced expiratory volume in one second; VC: vital capacity.

patients, the mean value of $V \mathrm{~T}$ was $1004 \mathrm{~mL}(\mathrm{SEM} \pm 76)$. The values of the slopes of the alveolar plateaux and the three dead spaces were not changed after $5 \mathrm{~min}$.

In the healthy controls, there was at $1 \mathrm{~L} V \mathrm{~T}$ a significantly positive correlation with height for the slopes of the alveolar plateaux as well as for the three dead spaces. The increase of the dead space estimates per 10 $\mathrm{cm}$ height was about $20 \mathrm{~mL}$. The linear regression equations were:

Slope alveolar plateaux $\left(\mathrm{kPa} \cdot \mathrm{L}^{-1}\right)=-1.9+(1.6 \times$ height in $\mathrm{m})$; $\mathrm{r}=0.61$, $\mathrm{p}$-value $<0.001$

$V \mathrm{D}, \mathrm{Bohr}(\mathrm{mL})=-73+(194 \times$ height in $\mathrm{m}) ; \mathrm{r}=0.67, \mathrm{p}-$ value $<0.001$

$V$ D,Fowler $(\mathrm{mL})=-169+(218 \times$ height in $\mathrm{m}) ; \mathrm{r}=0.68$, p-value $<0.001$

PIE $(\mathrm{mL})=-250+(263 \times$ height in $\mathrm{m}) ; \mathrm{r}=0.70, \mathrm{p}$-value $<0.001$

No relationship between the dead spaces at $1 \mathrm{~L} V \mathrm{~T}$ and age was found.

\section{Discussion}

For a clinical diagnosis of emphysema, we primarily used radiological criteria of the plain chest radiograph [13]. For further classification, this was integrated with the obstructive ventilatory defect, whereas TL,CO could only be measured in a subgroup. Together with the hyperinflation, these data nevertheless supported our classification, which has already been suggested by YERNAULT and Paiva [15].

Comparing four capnographic indices (slope of the alveolar plateau, $V \mathrm{D}, \mathrm{Bohr}, V \mathrm{D}$, Fowler and PIE) in healthy controls, asthma and emphysema patients resulted in: 1) different linear relationships with $V \mathrm{~T}$, enabling discrimination between no emphysema and emphysema using discriminant analysis, applied to intercept and slope of the relationship between $V \mathrm{D}$,Bohr and $V \mathrm{~T} ; 2)$ significant differences for all variables (compared to the mean values in healthy controls) for emphysema patients in breaths of $1 \mathrm{~L}$. Discrimination between no emphysema and emphysema was possible using discriminant analysis, applied to $V \mathrm{D}, \mathrm{Bohr}$ and the slope of the alveolar plateau of those breaths. $V \mathrm{D}, \mathrm{Bohr}$ and the slope of the alveolar plateau of a breath of $1 \mathrm{~L}$ were best related to the degree of airways obstruction. Increased frequencies above 15 breaths $\cdot \mathrm{min}^{-1}$ in healthy controls led to decrease of the values of the slopes of the alveolar plateaux and increases of the dead space variables in breaths of $1 \mathrm{~L}$; 3) no major impact on the values of the variables by preceding breaths; and 4) a linear relationship between all variables at $1 \mathrm{~L} \mathrm{VT}$ and height.

The primary mechanisms determining single breath washout have been extensively studied in inert gases and comprise serial and parallel inhomogeneity of lung units, sequential emptying and convection-diffusion interaction [16]. In case of $\mathrm{PCO}_{2}$ versus volume curves, ventilation-perfusion inhomogeneity and continuing gas exchange also influence the variables. For an explanation of our findings we mainly rely on studies describing the single breath $\mathrm{CO}_{2}$ wash-out [17].

In healthy controls, the negative relationship of the slope of the alveolar plateau with $V \mathrm{~T}$ can be explained by an increased contribution of the lower lung parts to the end of expiration during a deep breath from FRC [18]. Regional differences in gas exchange in humans in the upright position are characterized by relatively better ventilation than perfusion (low $\mathrm{PCO}_{2}$ ) in the top, and relatively better perfusion than ventilation at the bottom (high $\mathrm{PCO}_{2}$ ) [19]. During a deep breath, inspired air preferentially goes to the expanding lower lung [2023]. This means an increased ventilation/perfusion ratio in the basal part of the lung with increased $\mathrm{CO}_{2}$ dilution. The increased contribution of air from the lung base to the last part of expiration with increasing tidal volume then explains the flattening of the alveolar plateau.

The increase of anatomic dead space in healthy controls, estimated with the Fowler method in $\mathrm{N}_{2}$ and $\mathrm{CO}_{2}$ versus volume curves has been reported as $20-30 \mathrm{~mL}$ per litre of $V \mathrm{~T}$ increase [24, 25], which is in agreement with the values we found for $V D$,Fowler and PIE. The increase per litre for $V \mathrm{D}, \mathrm{Bohr}$ is larger, but we are not aware of published reports, probably because $V \mathrm{D}$,Bohr is usually expressed as $V \mathrm{D} / V \mathrm{~T}$ with normal values below $30 \%$, which decrease with increase of $V \mathrm{~T}[24,25]$. The larger values for the increase per litre of $V \mathrm{~T}$ of $V \mathrm{D}$,Bohr can be explained by the fact that besides the conducting airways, a part of the alveolar dead space contributes to its value.

Maximal discrimination between healthy controls and severely obstructed emphysema patients was possible when the slopes of the relationship between $V \mathrm{D}$,Bohr and $V \mathrm{~T}$ were plotted against the intercepts (fig. 2). In that case, the differences in absolute values for $V D$,Bohr at equal lung volumes and the changes with $V \mathrm{~T}$ have an additive effect on the discriminatory power. Almost all moderately obstructed emphysema patients were located at the emphysema side of the line, whereas the asthma patients were located at the healthy control side of the line, suggesting that this dead space measurement may be useful for the diagnosis of emphysema. The difference in pathophysiological mechanisms causing airways obstruction in emphysema and asthma may explain the 
different behaviour of the Bohr dead space. In case of emphysema, during tidal breathing there are large differences between badly and well-ventilated lung parts. The typical expiratory flow pattern with decrease of flow during expiration results in a wide phase 2 and a steep alveolar plateau. In contrast, the asthma patients with generalized bronchospasm show decreased inspiratory and expiratory flow with sinusoidal pattern, resulting only in an increased alveolar plateau.

The values for the slopes of the alveolar plateaux at $1 \mathrm{~L}$ volume showed the most significant differences between controls and the pathological states with airways obstruction, including asthma (table 3), whereas a quantitative relationship was found with the degree of airways obstruction (fig. 3). The higher $V D$, Bohr values at fixed $V \mathrm{~T}$ in the obstructive patients compared to the healthy controls can be attributed mainly to the steeper slopes of the alveolar plateau in these patients compared to healthy controls, which result in a larger contribution of alveolar dead space to $V D$,Bohr (fig. 2a). A quantitative relationship between the slope of the alveolar plateau and $V \mathrm{D} / V \mathrm{~T}$ was described by FLETCHER and coworkers [7, 8] and HofFBRAND [26] in COPD patients, whereas in emphysema patients a larger contribution of phase 2 to the expired volume was also found [4, 5]. The "effective" or physiological dead space is the most reliable index of effective dead space ventilation and requires arterial blood sampling [27]. Because our study was aimed at the comparison of non-invasively determined dead space estimates, physiological dead space was not determined.

According to Fowler [9], the anatomical dead space corresponds to the volume of the conducting airways down to the location where a large change in gas concentration occurs. Also, the PIE can be considered as an approach to detect the steepest slope of the curve. This explains the nearly identical findings for $V D$,Fowler and PIE. Distension of central airways and peripheral movement of the diffusion front at increasing $V \mathrm{~T}$ cause the increase of both $V$ D,Fowler and PIE. The resulting $P$ E, $\mathrm{CO}_{2}$-volume pattern then shows an increase of the phase 2 volume [4, 5]. At $1 \mathrm{~L}$ volumes there were significant differences compared to the controls only in the emphysema patients. This may be explained by the increased volume of phase 2 in these patients $[4,5]$, increasing both the PIE and $V$ D,Fowler estimates. WOLFF et al. [28] recently compared their PIE estimates with, among others, $V \mathrm{D}, \mathrm{Bohr}$. In spontaneously breathing subjects they found mean values for PIE and $V \mathrm{D}$, Bohr of $179 \mathrm{~mL}$ and $236 \mathrm{~mL}$, respectively, at a $V \mathrm{~T}$ of $967 \mathrm{~mL}$, which did not differ significantly from the data we found at $1 \mathrm{~L} V \mathrm{~T}$ : $152 \mathrm{~mL}$ and $210 \mathrm{~mL}$, respectively. In eight COPD patients, WoLfF et al. [28] found, in breaths with a volume of $569 \mathrm{~mL}$, values of PIE and $V \mathrm{D}$, Bohr of 183 and $217 \mathrm{~mL}$, respectively. If we extrapolate our dead space estimates in the severely obstructed emphysema patients to a $V \mathrm{~T}$ of $600 \mathrm{~mL}$, we find comparable values: $209 \mathrm{~mL}$ and $226 \mathrm{~mL}$ for PIE and $V \mathrm{D}$,Bohr, respectively.

Although an absence of breathing rate dependence on anatomic dead space estimates has been reported [29], most studies have revealed a slight increase with breathing frequency $[9,20,30]$, which is in accordance with our data. In healthy controls, an increased breathing frequency of 20 breaths $\cdot \mathrm{min}^{-1}$ even resulted in overlap of the values at $1 \mathrm{~L}$ with the values of emphysema patients for $V \mathrm{D}$,Fowler and PIE. An explanation can be given by assuming a shift of the diffusion front, the area where gas convection and diffusion meet, in peripheral direction during fast inspiration, and in central direction during slower breathing. During artificial ventilation in dogs, MEyer et al. [17] found an effect of expiratory flow on the anatomic dead space, which increased as flow increased. Slow expiration was found to exert similar effects as breathholding.

Although a significant decrease of $P$ ET, $\mathrm{CO}_{2}$ occurred during the manoeuvres in both healthy controls and severely obstructed emphysema patients, no significant change could be detected concerning the mean values of the three dead space estimates at the selected VTs $\geq 750 \mathrm{~mL}$ and within a range of $250 \mathrm{~mL}$. This means that our measurement procedure aimed at the estimation of a wide range of $V \mathrm{D}$ measurements in relation to $V \mathrm{~T}$ did not influence the accuracy of the final results.

Assuming that in healthy controls the physiological dead space almost equals the anatomic dead space, the relationship with height is in agreement with reports in the literature, which show an increase of the physiological dead space in healthy controls of $17 \mathrm{~mL}$ per 10 $\mathrm{cm}$ height [25], whereas we found about $20 \mathrm{~mL}$. In the present study, no significant relationship with age was found, but increase in physiological dead space was reported in one study to be 8 and $9 \mathrm{~mL}$ per 10 yrs of age in healthy women and men, respectively [30].

\section{Conclusion}

A plot of slope versus intercept of the relationship between Bohr dead space and tidal volume was most discriminating in the separation of healthy controls and asthma patients on the one hand and emphysema patients on the other. Almost equally discriminating was a combination of the slope of the alveolar plateau and Bohr dead space at a tidal volume of $1 \mathrm{~L}$. The slope of the alveolar plateau and Bohr dead space proved to be most significantly related to the degree of airways obstruction and to show less overlap with values in healthy controls by variation in breathing frequency. Fowler dead space and pre-interface expirate are almost identical derivates of the expiratory carbon dioxide tension-volume curve, both linked to the volume of the conducting airways, whereas Bohr dead space is strongly influenced by the alveolar dead space, which probably explains the larger diagnostic applicability.

\section{References}

1. Van Meerten RJ. Expiratory gas concentration curves for examination of uneven distribution of ventilation and perfusion in the lung. Second communication: experiments. Respiration 1971; 28: 167-185.

2. Smidt U. Emphysema as possible explanation for the alteration of expiratory $\mathrm{PO}_{2}$ and $\mathrm{PCO}_{2}$ curves. Bull Eur Physiopathol Respir 1976; 12: 605-624.

3. Smidt U, Worth H. Diagnostik des Lungenemphysems aus exspiratorischen $\mathrm{CO}_{2}$-Partialdruckkurven mit Hilfe eines Mikroprozessors. Biomed Tech 1978; 22: 357-358. 
4. Worth H. Expiratory partial pressure curves in the diagnosis of emphysema. Bull Eur Physiopathol Respir 1986; 22: 191-199.

5. Kars AH, Goorden G, Stijnen T, Bogaard JM, Verbraak AFM, Hilvering C. Does phase 2 of the expiratory $\mathrm{PCO}_{2}$ versus volume curve have diagnostic value in emphysema patients? Eur Respir J 1995; 8: 86-92.

6. West JB, Fowler KT, Hugh-Jones P, O'Donnell TV. The measurement of the inequality of ventilation and of perfusion in the lung by the analysis of single expirates. Clin Sci 1957; 16: 549-565.

7. Fletcher R. The single breath test for carbon dioxide. Thesis. Berlings, Arlöv, Sweden, 1980.

8. Fletcher R, Jonson B, Cumming G, Brew J. The concept of deadspace with special reference to the single breath test for carbon dioxide. Br J Anaesth 1984; 56 : 77-87.

9. Fowler WS. Lung functions studies. II. The respiratory dead space. Am J Physiol 1948; 154: 405-416.

10. Bartels J, Severinghaus JW, Forster RE, Briscoe WA, Bates DV. The respiratory dead space measured by single breath analysis of oxygen, carbon dioxide, nitrogen or helium. J Clin Invest 1954; 33: 41-48.

11. Wolff G, Brunner JX. Series dead space volume assessed as the mean value of a distribution function. Int J Clin Mon Comp 1984; 1: 177-181.

12. American Thoracic Society. Standards for the diagnosis and care of patients with chronic obstructive pulmonary disease (COPD) and asthma. Am Rev Respir Dis 1987; 136: 225-243.

13. Pratt PC. Role of conventional chest radiography in diagnosis and exclusion of emphysema. Am J Med 1987; 82: 998-1006.

14. Quanjer PH. Standardized lung function testing. Report Working Party "Standardization of lung function tests", European Community for Coal and Steel, Luxembourg. Bull Eur Physiopath Resp 1983; 19, Suppl. 5: 1-95.

15. Yernault JC, Paiva M. The in vivo diagnosis of emphysema: an uncompletely resolved issue. Bull Eur Physiopathol Resp 1986; 22: 95-97.

16. Engel LA. Intraregional gas mixing and distribution. In: Engel LA, Paiva M, eds. Gas mixing and Distribution in the Lung. Lung Biology in Health and Disease, vol. 25; New York, Marcel Dekker, Inc. 1985: pp. 287-358.
17. Meyer M, Mohr M, Schulz H, Piiper J. Sloping alveolar plateaus of $\mathrm{CO}_{2}, \mathrm{O}_{2}$, and intravenously infused $\mathrm{C}_{2} \mathrm{H}_{2}$ and $\mathrm{CHClF}_{2}$ in the dog. Resp Physiol 1990; 81: 137-152.

18. Dolffuss RE, Milic-Emili J, Bates DV. Regional ventilation of the lung, studied with boluses of Xenon ${ }^{133}$. Resp Physiol 1967; 2: 234-246.

19. West JB. Regional differences in gas exchange in the lung of the erect man. J Appl Physiol 1962; 17: 893-898.

20. Ball WC, Stewart PB, Newsham LGS, Bates DV. Regional pulmonary function studied with Xenon ${ }^{133}$. J Clin Invest 1962; 41: 519-531.

21. Milic-Emili J, Henderson JAM, Dolovich MB, Kaneko $\mathrm{K}$. Regional distribution of inspired gas in the lung. $J$ Appl Physiol 1966; 21: 749-759.

22. Kaneko K, Milic-Emili J, Dolovich MB, Dawson A, Bates DV. Regional distribution of ventilation and perfusion as a function of body position. J Appl Physiol 1966; 21: 767-777.

23. Bryan AC, Bentvoglio LG, Beerel F, MacLeish H, Zidulka A, Bates DV. Factors affecting regional distribution of ventilation and perfusion in the lung. J Appl Physiol 1964; 19: 395-402.

24. Bouhuys A. Respiratory dead space. Handbook of Physiology. Washington DC, American Physiological Society, 1964. Section 3, Respiration, Volume 1; pp. 28: 699-714.

25. Nunn JF. Applied Respiratory Physiology. 4th Edn. Oxford, Butterworth-Heinemann Ltd, 1993.

26. Hoffbrand BI. The expiratory capnogram: a measure of ventilation-perfusion inequalities. Thorax 1966; 21: 518-523.

27. Enghoff H. Volumen inefficax. Bemerkungen zur Frage des schädlichen Raumes. Upsala Läkaref Förh 1938; 44: 191-218.

28. Wolff G, Brunner JX, Weibel W, Bowes CL, Muchenberger R, Bertschmann W. Anatomical and series dead space volume: concept and measurement in clinical praxis. Appl Cardiopulm Pathophys 1989; 2: 299-307.

29. Lifshay A, Fast CW, Glazier JB. Effects of changes in respiratory pattern on physiological dead space. J Appl Physiol 1971; 31: 478-483.

30. Harris EA, Hunter ME, Seelye ER, Vedder M, Whitlock RML. Prediction of the physiological dead space in resting normal subjects. Clin Sci 1973; 45: 375-386. 